\title{
Neurodevelopmental Outcomes of Very-Low-Birth- Weight Infants without Severe Brain Lesions and Impact of Postnatal Steroid Use: A Single-Center Korean Study
}

Mun Hui Jeong, $\mathrm{MD}^{1}$, Seong Hee Jeong, $\mathrm{MD}^{1}$, Su Jeong Park, $\mathrm{MD}^{2}$, Narae Lee, $\mathrm{MD}^{1}$, Mi-Hye Bae, $\mathrm{MD}^{2}$, Kyung-Hee Park, MD, $\mathrm{PhD}^{2,3}$, Shin-Yun Byun, MD, $\mathrm{PhD}^{1,3}$, Choongrak Kim, $\mathrm{PhD}^{4}$, and Young Mi Han, MD, PhD ${ }^{1,3}$

${ }^{1}$ Department of Pediatrics, Pusan National University Children's Hospital, Yangsan, Korea

${ }^{2}$ Department of Pediatrics, Pusan National University Hospital, Busan, Korea

${ }^{3}$ Department of Pediatrics, Pusan National University School of Medicine, Yangsan, Korea

${ }^{4}$ Department of Statistics, Pusan National University, Busan, Korea

\section{ABSTRACT}

Purpose: We used the Bayley Scales of Infant and Toddler Development (BSID)-III to analyze the incidence and risk factors of developmental delay in very-low-birthweight infants without severe brain lesions. We further examined the correlation between the cumulative dexamethasone dose and developmental assessment results. Methods: We retrospectively analyzed data of preterm infants (birth weight $<1,500$ g) admitted to our neonatal intensive care unit between January 2014 to December 2020. The BSID-III scores obtained between the corrected ages of 12 and 24 months and after 24 months were analyzed. Developmental delay was defined as a composite score of $<85$ for the cognition, language, and motor domains. Univariate and multivariate analyses of developmental delay risk factors and developmental changes from the first to second BSID-III were performed. Correlations between the accumulated dexamethasone dose used for bronchopulmonary dysplasia (BPD) and the first and second test scores were analyzed.

Results: Seventy-one and thirty-six infants completed the first and second tests, respectively. In both tests, developmental delay was most commonly observed in the language domain $(26.8 \%, 47.2 \%)$. In multivariate analysis, mild BPD was identified as a developmental delay risk factor $(P<0.05)$, whereas prenatal steroid use reduced the developmental delay risk $(P<0.05)$. All domain scores were lower in the second test than in the first test. The cognition and language domain scores in the second test decreased with increasing cumulative dexamethasone doses.

Conclusion: Very-low-birth-weight infants typically experience language delay, which can persist as they age.

Key Words: Infant, very low birth weight; Developmental disabilities; Dexamethasone

Received: 10 January 2022

Revised: 9 February 2022

Accepted: 15 February 2022

Correspondence to: Young Mi Han,

$\mathrm{MD}, \mathrm{PhD}$

Department of Pediatrics, Pusan

National University Children's

Hospital, Pusan National University

School of Medicine, 20 Geumo-ro,

Mulgeum-eup, Yangsan 50612, Korea

Tel: +82-55-360-2180

Fax: +82-55-360-2181

E-mail: skybluehym@gmail.com

Copyright(c) 2022 By Korean Society of Neonatology

This is an Open-Access article distributed under the terms of the Creative Commons Attribution Non-Commercial License (http:// creativecommons.org/licenses/by-nc/4.0), which permits unrestricted non-commercial use, distribution, and reproduction in any medium, provided the original work is pro perly cited. 


\section{INTRODUCTION}

The survival rate of very-low-birth-weight infants (VLBWIs) is increasing, while the incidence of major complications in such infants is decreasing in many countries owing to medical advances and the development of various drugs and respiratory assist devices ${ }^{1,2)}$. One study that analyzed the survival trend among extremely preterm neonates in the United States over the last two decades reported survival rates of $80 \%$ and $90 \%$ for neonates born at 25 and 27 weeks, respectively. However, the survival rates for neonates discharged without major morbidities were only $20 \%$ and $50 \%$, respectively, indicating that chronic complications remain a challenge to be overcome in preterm infants ${ }^{2)}$.

For preterm infants, the primary goal is survival and independent and autonomous living as adults. Severe brain lesions, which commonly include severe intraventricular hemorrhage (IVH) and periventricular leukomalacia (PVL) are major risk factors for poor development. Brain ultrasonography and, if needed, brain magnetic resonance imaging (MRI) can be used to detect severe brain lesions during hospitalization. An imaging study reported that preterm infants without severe brain lesions can still expe rience severe developmental delay ${ }^{3)}$. Bronchopulmonary dy splasia (BPD), which increases in incidence as the number of weeks of survival of preterm infants decreases, affects neurode velopmental outcomes ${ }^{4}$. Currently, no treatment is available for this chronic disease. Postnatal steroids were actively used to wean infants off ventilator support until the mid-1990s ${ }^{2}$; however, they have only been used as a last resort since the report of cerebral palsy (CP) as a long-term complication of postnatal steroid use. Currently, postnatal steroids are used for a short period, not too early after birth, in infants with unfavorable conditions ${ }^{5}$. Normal development is necessary for VLBWIs, who are at a high risk of developing BPD, to enjoy a good quality of life as they grow older; however, this cannot be guaranteed owing to the limitations of the available treatments.

Imaging to examine severe brain lesions is often performed as a screening procedure, and developmental follow-up of individual infants after discharge is necessary. The Bayley Scales of Infant and Toddler Development (BSID) is one of the most widely used developmental assessment tools. The BSID-III assesses development across five domains (cognition, receptive language, expressive language, gross motor, and fine motor), in greater detail than does the BSID-II ${ }^{6)}$. It evaluates whether infants are developing at a rate appropriate for their corrected age in months, and the scores determine whether such infants require rehabilitative therapy. The Korean Neonatal Network (KNN) recommends completing the BSID-III test between the corrected ages of 18 and 24 months; and at 3 years. In reality, most infants are lost to follow-up after discharge; as a result, few studies have been conducted on the development of VLBWIs.

Understanding the developmental state of preterm infants is important to ensure not only survival, but also a good quality of life. This study used BSID-III scores to analyze the incidence and risk factors of developmental delay and developmental changes observed in VLBWIs without severe brain lesions who were discharged from a single institution during a 7-year period. Additionally, this study investigated whether the cumulative dexamethasone dose and developmental assessment results were correlated with each other.

\section{MATERIALS AND METHODS}

\section{Study population}

Data collected from preterm infants with a birth weight of $<1,500 \mathrm{~g}$ who were admitted to the neonatal intensive care unit (NICU) of our institution between January 2014 and December 2020 were retrospectively analyzed. Infants who completed the BSID-III test at the corrected age of 12 months after discharge were selected. Those with severe brain lesions, defined as $\mathrm{IVH}$ of grade III or higher, PVL, or brain deformities detected on ultrasonography or brain MRI, were excluded.

\section{Study design}

The BSID-III scores obtained between the corrected ages of 12 and 24 months and after 24 months were analyzed to examine development at the corrected ages of 1 and 2 years, respectively. Developmental delay was defined by a composite score of $<85$ on each of the following domains: cognition, language, and motor ${ }^{7)}$; It was deemed severe when the composite score for each domain was $\leq 69$. The language composite scores consist of a combination of expressive and receptive language subscales, while the motor composite scores consist of gross and fine motor subscales. Univariate and multivariate analyses were conducted to determine the risk factors for developmental delay. Additionally, the developmental changes observed in infants who completed both BSID-III tests were examined. 
To investigate the effect of dexamethasone use on BPD de velopment, we analyzed the correlations between the cumula tive dose of dexamethasone and the first and second BSID-III scores.

\section{Data collection and definition}

Gestational age, sex, multiple gestations, birth weight, head circumference, delivery mode, 1- and 5-minute Apgar scores, and prenatal steroid use were examined as perinatal factors po tentially affecting developmental delay. Maternal age, hyperten sion, and gestational diabetes were also examined. In terms of morbidities of the enrolled preterm infants in the NICU, we examined respiratory distress syndrome, BPD, postnatal steroid use, and retinopathy of prematurity (ROP), for which an intravitreal injection of bevacizumab or laser therapy was performed; patent ductus arteriosus, for which pharmacotherapy or ligation was performed; necrotizing enterocolitis for which a laparotomy was performed; inguinal hernia surgery; culture-proven sepsis; referred otoacoustic emission or auditory brainstem response; and weight and head circumferences at the time of discharge ${ }^{8)}$. The presence and severity of BPD were determined on the basis of the need for oxygen therapy 28 days after birth and at the corrected age of 36 weeks. BPD was considered mild when the infant required oxygen therapy at 28 days after birth but no longer required oxygen therapy after the corrected age of 36 weeks; moderate when the infant required $<30 \%$ oxygen administration; and severe when the infant required $\geq 30 \%$ oxygen administration or positive-pressure ventilation ${ }^{9)}$.

Postnatal steroids were used for two main reasons in the NICU. Hydrocortisone was administered at $3 \mathrm{mg} / \mathrm{kg} /$ day for refractory hypotension not treated by dopamine administered at $\geq 10 \mu \mathrm{g} /$ $\mathrm{kg} / \mathrm{min}$. The dose of hydrocortisone was gradually reduced, and administration was stopped once the blood pressure stabilized. Dexamethasone was administered from at least 3 weeks of age when the infant was exposed to oxygen therapy or positivepressure ventilation for a long period after being diagnosed with BPD or when progression to severe BPD was predicted and weaning from invasive mechanical ventilation was deemed difficult even before 28 days after birth. Two administration schemes were used and selected by neonatologists based on the patient's lung condition and the need for respiratory assistance: 10-day administration (with an initial dose of $0.1 \mathrm{mg} / \mathrm{kg} /$ day gradually reduced over 10 days or a total dose of $0.55 \mathrm{mg} / \mathrm{kg}$ ) or 2-week administration (with an initial dose of $0.25 \mathrm{mg} / \mathrm{kg} /$ day gradually reduced over 14 days or a total of $1.62 \mathrm{mg} / \mathrm{kg}$ ). When the infants could not be weaned off mechanical ventilation even after 3 to 4 days of dexamethasone administration, steroid administration was deemed ineffective and was ceased. When weaning from mechanical ventilation was delayed, steroids were administered at regular intervals.

\section{Statistical analysis}

All analyses were performed using R version 3.6.1 (RCore Team 2017, R Foundation for Statistical Computing, Vienna, Austria; https://www.R-project.org/). The clinical characteristics of the study population were described as means \pm standard deviations or numbers (percentages) of cases. Univariate and multivariate logistic regression models were used to identify the risk factors for developmental delay, and associations were presented as odds ratio (OR) and 95\% confidence interval (CI). Pearson correlation analysis was performed to analyze the relationship between the total accumulated dose of dexamethasone and the composite score for the development domain. Furthermore, a simple linear regression model was fitted for the BSID-III test scores within and by each development domain after the corrected age of 24 months. Statistical significance was set at $P<0.05$.

\section{RESULTS}

\section{Study population}

A total of 254 VLBWIs weighing $<1,500 \mathrm{~g}$ were admitted to the NICU of our institution between January 2014 and December 2020. Of these, 149 infants who did not complete the BSID-III test, 1 infant who completed the Korean Denver Development Screening Test II, and 2 infants who completed the BSID-III at times other than during the specified period were excluded. The remaining 102 infants completed their first BSID-III test at the corrected ages of 12 to 24 months. Thirty-one infants with severe brain lesions (six with IVH grade III or higher, 21 with PVL, and four with IVH grade III or higher with PVL) were excluded. Finally, 71 infants were included in this study (Figure 1). The mean gestational age and birth weight of the included infants were $29.3 \pm 2.6$ weeks and $1,087.5 \pm 252.4 \mathrm{~g}$, respectively (Tables 1 , 2). Thirty-six infants completed the second BSID-III test after the corrected age of 24 months (mean corrected age, 28.2 \pm 6.5 ). 
VLBW infants born in 2014-2020 ( $\mathrm{n}=254)$

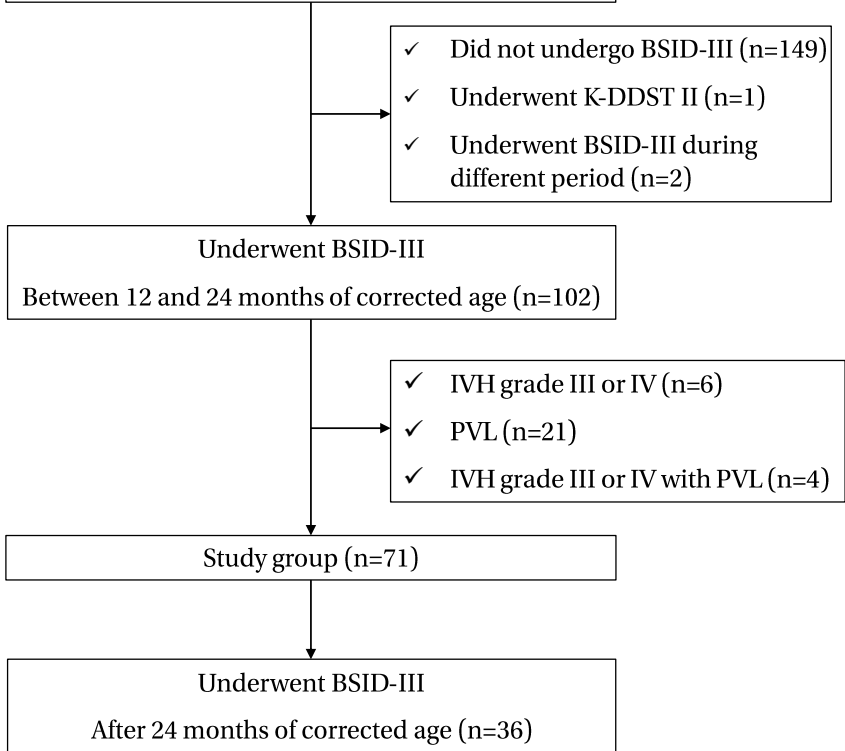

Figure 1. Enrollment of the study group. Abbreviations: VLBW, very low birth weight; BSID, Bayley Scales of Infant and Toddler Development; K-DDST, Korean Denver Developmental Screening Test; IVH, intraventricular hemorrhage; PVL, periventricular leukomalacia.

Table 1. Demographic Characteristics of the Enrolled Preterm Infants $(\mathrm{n}=71)$

\begin{tabular}{lc}
\hline Variable & Value \\
\hline Neonatal characteristics & $29.3 \pm 2.6$ \\
Gestational age $(\mathrm{wk})$ & $34(47.9)$ \\
Male sex & $18(23.4)$ \\
Multiple gestation & $1,087.5 \pm 252.4$ \\
Birth weight $(\mathrm{g})$ & $22.1 \pm 9.6$ \\
Birth head circumference $(\mathrm{cm})(\mathrm{n}=63)$ & $56(78.9)$ \\
Cesarean section & $4.1 \pm 1.2$ \\
1-minute Apgar score & $6.4 \pm 1.0$ \\
5-minute Apgar score & $53(74.7)$ \\
Antenatal corticosteroid & \\
Maternal characteristics & $34.1 \pm 4.5$ \\
Maternal age (yr) & $23(32.4)$ \\
Maternal hypertension & $5(7.0)$ \\
Gestational diabetes & \\
\hline
\end{tabular}

Values are expressed as mean \pm standard deviation or number (\%).

\section{Neurodevelopmental assessment results}

Seventy-one infants without severe brain lesions who completed the BSID-III test completed their first test at the mean corrected age of $14.7 \pm 3.3$ months. Developmental delay was most commonly observed in the language domain $(n=19,26.8 \%)$,
Table 2. Morbidities of the Enrolled Preterm Infant in the Neo natal Intensive Care Unit $(\mathrm{n}=71)$

\begin{tabular}{lc}
\hline Variable & Value \\
\hline RDS & $57(80.3)$ \\
BPD & \\
BPD, mild & $7(9.9)$ \\
BPD, moderate to severe & $44(62.0)$ \\
Postnatal corticosteroid & $38(53.5)$ \\
Hydrocortisone and dexamethasone & $10(14.1)$ \\
Dexamethasone & $27(38.0)$ \\
Prednisolone & $1(1.4)$ \\
PDA & $28(39.4)$ \\
ROP & $8(11.3)$ \\
NEC, laparotomy & $3(4.2)$ \\
Inguinal hernia, repair operation & $17(23.9)$ \\
Blood culture proven sepsis & $17(23.9)$ \\
Abnormal OAE, ABR & $4(5.6)$ \\
DEHSI & $24(33.8)$ \\
Discharge weight (g) & $2,803.5 \pm 666.5$ \\
Discharge head circumference $(\mathrm{cm})(\mathrm{n}=69)$ & $32.3 \pm 4.9$
\end{tabular}

Values are expressed as number (\%) or mean \pm standard deviation.

Abbreviations: RDS, respiratory distress syndrome; BPD, bronchopul monary dysplasia; PDA, patent ductus arteriosus; ROP, retinopathy of prematurity; NEC, necrotizing enterocolitis; OAE, otoacoustic emission; $\mathrm{ABR}$, auditory brainstem response; DEHSI, diffuse excessive high signal intensity.

followed by the cognition ( $\mathrm{n}=17,23.9 \%)$ and motor domains $(n=13,18.3 \%)$. However, in the comparison of the mean com posite scores and the percentage of infants with severe develop. mental delay among the domains, the motor domain had the lowest mean composite score (70.9 \pm 7.0$)$ and involved the highest number of infants with severe developmental delay $(n=6,8.5 \%)$ (A in Table 3).

Of the 71 infants analyzed, 36 completed the second BSID-III test at a mean corrected age of $28.2 \pm 6.5$ months. Developmental delay was most commonly observed in the language domain $(n=17,47.2 \%)$. The language domain had the lowest mean composite score $(68.9 \pm 9.7)$ and involved the highest percentage of infants with severe developmental delay $(n=7,19.4 \%)$ (B in Table 3).

\section{Predictors of adverse neurodevelopmental outcome}

The risk factors for developmental delay were analyzed for each BSID-III domain. In the multivariate logistic regression analysis, mild BPD was identified as a risk factor of cognitive developmental delay (OR, 13.21; 95\% CI, 1.75 to $139.35 ; P=0.02$ ) 


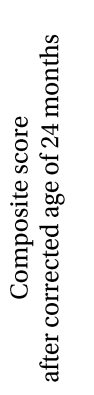

A
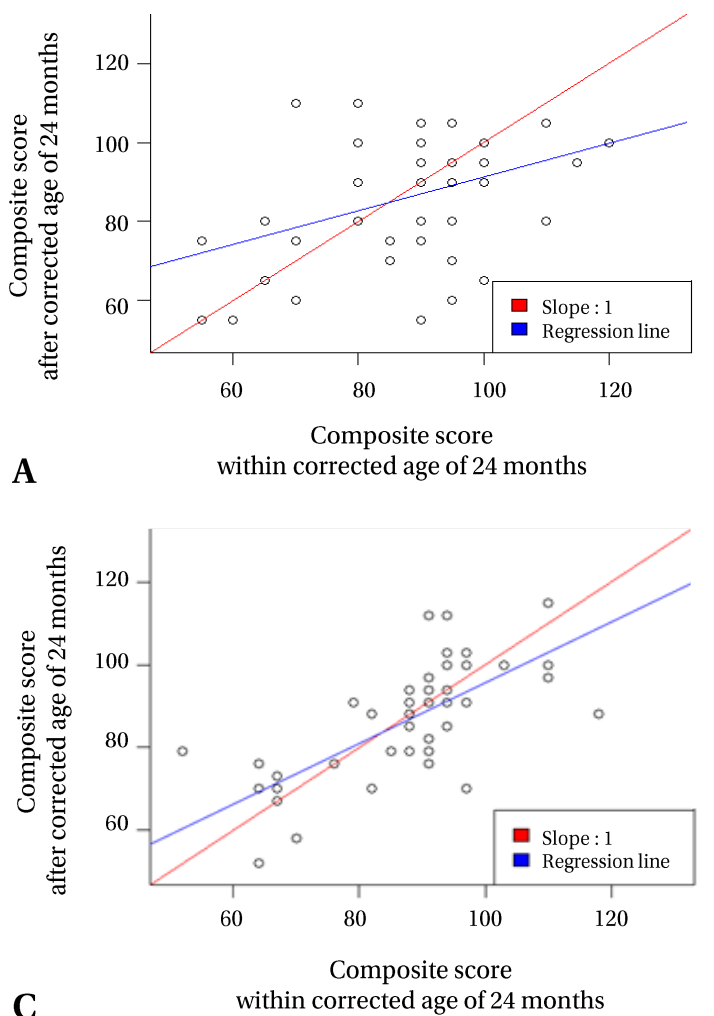

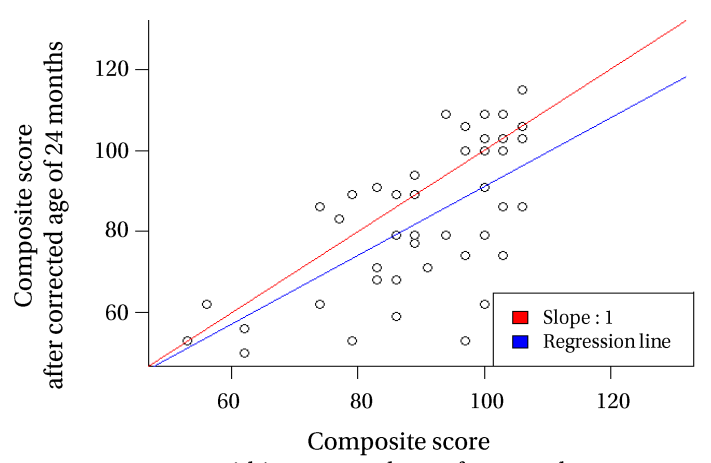

B

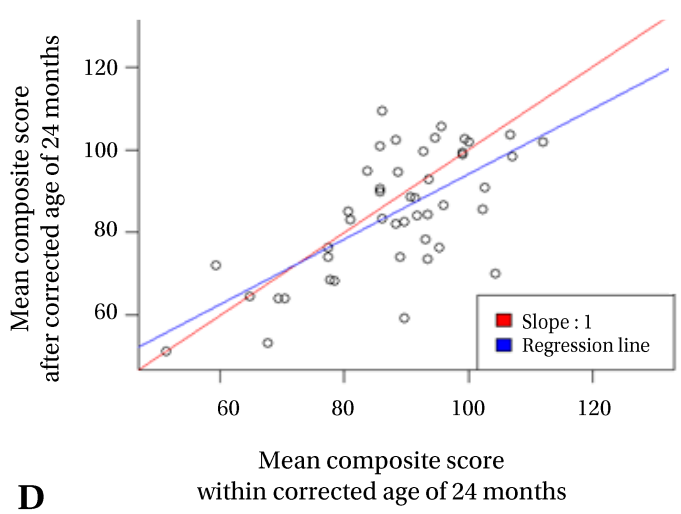

Figure 2. Simple linear regression for the results of the Bayley Scales of Infants and Toddler Development within and after 'the' corrected 'age' of 24 months according to the development domain. (A) Cognition domain, (B) language domain, (C) motor domain, (D) mean composite score of three domains.

between the corrected ages of 12 and 24 months, whereas prenatal steroid administration was found to reduce the risk of cognitive developmental delay (OR, 0.19; $95 \% \mathrm{CI}, 0.03$ to 0.84 ; $P=0.04$ ) (Table 4). In the univariate analysis, prenatal steroid administration was found to reduce the risk of language developmental delay (OR, $0.38 ; 95 \% \mathrm{CI}, 0.14$ to $0.95 ; P=0.05$ ), and ROP was identified as a risk factor for motor developmental delay (OR, 6.00; 95\% CI, 1.23 to 29.96; $P=0.02$ ). However, no significant risk factors were identified in the multivariate logistic regression analysis for either domain. The univariate and multivariate logistic regression analyses revealed no significant risk factors for cognitive or motor developmental delay after the corrected age of 2 years. Severe BPD was identified as a risk factor for language developmental delay (OR, 6.75; 95\% CI, 1.38 to $50.81 ; P=0.03$ ) only in univariate analysis. Postnatal dexamethasone use had no significant effect on the development delay for each domain in the univariate and multivariate logistic regression analyses at the corrected ages of 1 and 2 years.
Table 3. Overview of the Bayley Scales of Infant and Toddler Development Test Outcome of the Enrolled Infants

\begin{tabular}{lccc}
\hline Variable & Cognition & Language & Motor \\
\hline $\begin{array}{l}\text { A. Between the corrected ages of } 12 \\
\text { and } 24 \text { months (n=71) }\end{array}$ & & & \\
No delay & $54(76.1)$ & $52(73.2)$ & $58(81.7)$ \\
Mean \pm SD & $98.1 \pm 10.1$ & $97.5 \pm 7.7$ & $98.1 \pm 9.1$ \\
Delay & $17(23.9)$ & $19(26.8)$ & $13(18.3)$ \\
$\quad$ Mean \pm SD & $72.9 \pm 8.1$ & $75.4 \pm 6.5$ & $70.9 \pm 7.0$ \\
Severe delay & $4(5.6)$ & $3(4.2)$ & $6(8.5)$ \\
Mean \pm SD & $61.3 \pm 4.8$ & $63.0 \pm 1.7$ & $65.0 \pm 2.5$ \\
B. After the corrected age of 24 & & & \\
months (n=36) & & & \\
No delay & $22(61.1)$ & $19(52.8)$ & $25(69.4)$ \\
Mean $\pm S D$ & $98.0 \pm 6.8$ & $90.0 \pm 9.3$ & $95.3 \pm 7.6$ \\
Delay & $14(38.9)$ & $17(47.2)$ & $11(30.6)$ \\
$\quad$ Mean $\pm S D$ & $72.5 \pm 8.0$ & $68.9 \pm 9.7$ & $70.8 \pm 8.9$ \\
Severe delay & $3(8.3)$ & $7(19.4)$ & $3(8.3)$ \\
Mean $\pm S D$ & $60.0 \pm 5.0$ & $59.4 \pm 7.0$ & $59.0 \pm 7.6$
\end{tabular}

Values are expressed as number (\%) or mean \pm standard deviation. Abbreviation: SD, standard deviation. 
Table 4. Univariate and Multivariate Logistic Regression for Cognitive Outcomes of Preterm Infants between the Corrected Ages of 12 and 24 Months $(\mathrm{n}=71)$

\begin{tabular}{|c|c|c|c|c|c|c|}
\hline \multirow{2}{*}{ Variable } & \multicolumn{3}{|c|}{ Univariate logistic } & \multicolumn{3}{|c|}{ Multivariate logistic } \\
\hline & OR & $95 \% \mathrm{CI}$ & $P$-value & OR & $95 \% \mathrm{CI}$ & $P$-value \\
\hline Gestational age (wk) & 0.98 & $0.95-1.01$ & 0.30 & 1.07 & $0.98-1.19$ & 0.13 \\
\hline Birth weight (g) & 1 & $0.99-1.00$ & 0.02 & 0.99 & $0.99-1.00$ & 0.01 \\
\hline Antenatal corticosteroid & 0.42 & $0.15-1.08$ & 0.08 & 0.19 & $0.03-0.84$ & 0.04 \\
\hline BPD, mild & 5.23 & $1.03-29.45$ & 0.04 & 13.21 & $1.75-139.35$ & 0.02 \\
\hline
\end{tabular}

The multivariate analysis included parameters that showed association in the univariate analysis. Abbreviations: OR, odds ratio; CI, confidence interval; BPD, bronchopulmonary dysplasia.

\section{Developmental changes at a corrected age of 1 and 2 years}

Thirty-six infants completed the two BSID-III tests. The trends in developmental delay were analyzed by comparing the first and second BSID-III tests. The infants scored lower in the second test than in the first test across all domains, indicating developmental delay (Figure 2).

\section{Effects of dexamethasone use on the developmental assessment results}

Of the 71 infants who completed the first BSID-III test, 37 were administered dexamethasone. The time of the first administration was $48.8 \pm 19.6$ days (range, 23 to 111) after birth, and the total duration of administration was $21.4 \pm 14.3$ days (range, 3 to 75 ). The cumulative dose of dexamethasone used was $3.8 \pm 3.7$ $\mathrm{mg} / \mathrm{kg}$ (range, 0.5 to 21.0 ).

Among the infants who completed the second BSID-III test, 23 had a history of dexamethasone use. The first administration was performed $48.5 \pm 19.7$ days (range, 27 to 111 ) after birth, and the total duration of administration was $19.1 \pm 12.3$ days (range, 3 to 50 ). The cumulative dose of dexamethasone was $2.8 \pm 1.9 \mathrm{mg} /$ $\mathrm{kg}$ (range, 0.5 to 7.0 ).

No significant correlation was observed between the cumulative dose of dexamethasone and developmental delay based on the first BSID-III test scores; meanwhile, the second BSIDIII scores for the cognition $(P=0.03)$ and language domains $(P=$ 0.02 ) were significantly decreased as the cumulative dose of dexamethasone increased (Figure 3).

\section{DISCUSSION}

Compared with full-term infants, preterm infants have underdeveloped executive functions, reduced receptive and expressive vocabularies, and poor motor function. The later a developmental

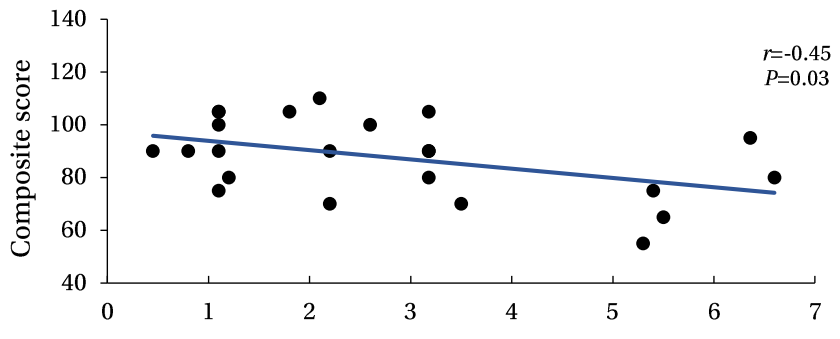

A Total accumulated dose of dexamethasone $(\mathrm{mg} / \mathrm{kg})$
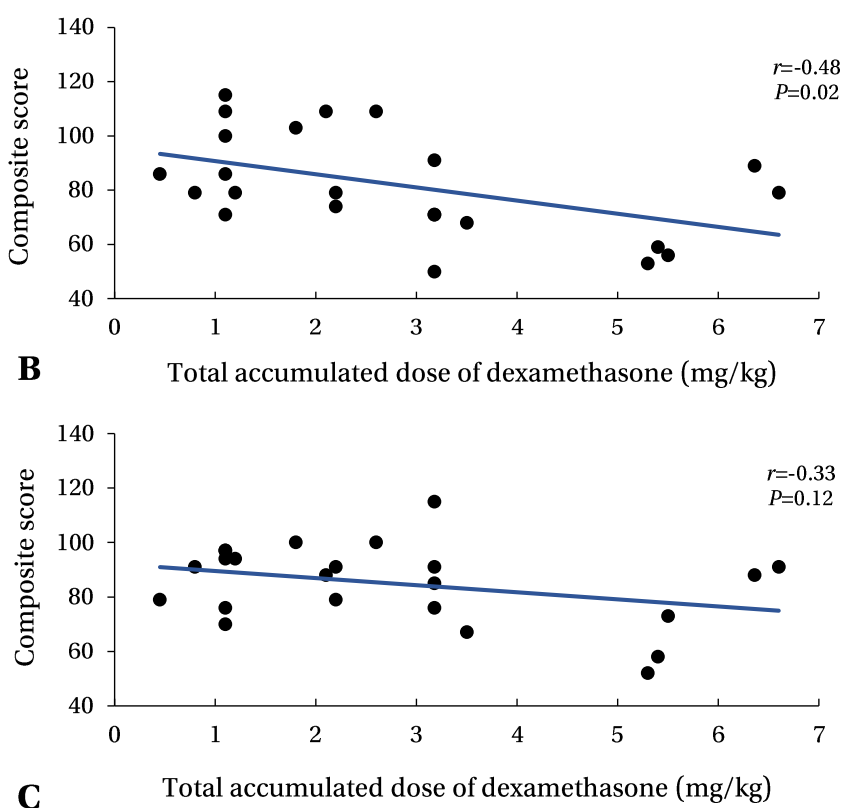

Figure 3. Scatter plots and Pearson correlation coefficients $(r)$ between the total accumulated dose of dexamethasone and composite score by development domains after the corrected age of 24 months. (A) Cognition domain, (B) language domain, (C) motor domain.

delay is managed, the more likely it is that a preterm infant will experience cognitive, language, and motor disabilities that can require additional treatment. Therefore, early developmental assessment of preterm infants is important ${ }^{10,11)}$. However, of the 254 VLBWIs treated in the NICU from 2014 to 2020 in this retrospective 
study, only $102(40.2 \%)$ and $36(14.2 \%)$ completed the BSID-III tests at the corrected ages of 1 and 2 years, respectively. The KNN, started in 2013, is a web-based VLBWI registration project with 75 participating hospitals, which currently includes approximately $70 \%$ of all VLBWIs registered across Korea ${ }^{12}$. Data from the KNN showed a poor developmental follow-up rate for preterm infants in South Korea. Only $\mathbf{2 8 . 7 \%}$ and $\mathbf{1 1 . 9 \%}$ of all VLBWIs completed a short-term developmental assessment between the corrected ages of 18 and 24 months in 2014 and a long-term assessment between the ages of 33 and 38 months in 2013, respectively ${ }^{13)}$. Since the launch of the KNN and the strong encouragement of hospital participation, the incidence of short- and long-term developmental assessments has increased to $40.8 \%$ and $17.5 \%$, respectively, for infants born in 2018 ${ }^{14)}$. Although VLBWIs are a high-risk group for developmental delay, irrespective of the presence of brain disease, the follow-up rate for VLBWIs re mains low at our institution and across Korea. Mothers who give birth prematurely are mostly concerned about the survival of their infants and their post-survival development. They feel hopeful that their infants show no abnormalities on brain imaging. During hospitalization, neonatologists must help parents recognize the necessity of developmental assessments by emphasizing the importance of long-term follow-up on neuro development.

In this study, the incidence of language developmental delay was $26.8 \%$ and $47.2 \%$ at the corrected ages of 1 and 2 years, respectively. Language developmental delay is the most com. mon and long-lasting developmental delay. This result is consistent with a report by the $\mathrm{KNN}$, which stated that language developmental delay had the highest incidence of $26.5 \%$ to $48.7 \%$ among other types of delays ${ }^{13-17)}$. Similarly, a study examining infants born without severe brain lesions between 2013 and 2015 reported that language developmental delay had the highest incidence $(20.7 \%)$, and severe language developmental delay also had a high incidence $(4.2 \%)^{18)}$. Prior studies have reported that infants with a clear language developmental delay without neurological deficits continue to show language developmental delay until they reach school age ${ }^{19)}$. Normal brain structure, articulators, and sensory-motor system are prerequisites for normal language development. Moreover, exposure to social stimuli and normal cognitive function are required to use lang uage to communicate. Problems with any of these factors can lead to a language developmental delay, which may later be accompanied by behavioral disorders, such as attention deficit hyperactivity disorder and autism spectrum disorder, as well as learning disabilities. Structural assessment of the brain alone does not determine whether an infant will undergo normal language development. Language development must be re gularly assessed because language developmental delay may be an early sign of other neurodevelopmental disabilities.

Low gestational age, low birth weight, low Apgar score, BPD, ROP, IVH, and PVL are known risk factors for developmental delays. Conversely, several studies have reported that prenatal steroid use reduce the risk of developmental delay ${ }^{11,20-24)}$. In our study, prenatal steroid use contributed to normal development. However, in the multivariate analysis of the risk factors for developmental delay, mild BPD was identified as a significant risk factor for cognitive developmental delay at the corrected age of 1 year. This result is inconsistent with those of previous studies that have identified severe BPD as a risk factor for developmental delay $^{4,25)}$. This discrepancy in the results may be attributed to the small sample size used in our study or to a bias caused by factors not considered herein. Thus, it cannot be concluded that mild BPD is a better predictor of poor neurodevelopment than moderate-to-severe BPD.

Dexamethasone exerts adverse effects on neurodevelopment and is more dangerous the earlier it is used ${ }^{26,27)}$. Davidovitch et al. ${ }^{28)}$ reported that $113(2.3 \%)$ of 4,963 VLBWIs were diagnosed with autism spectrum disorder, suggesting a significant association between postnatal steroid use and autism spectrum disor der. Conversely, a recent meta-regression study reported that infants at a higher risk of developing BPD had increased rates of survival free of CP after postnatal corticosteroid therapy ${ }^{29)}$, suggesting the possibility of using minimal doses of postnatal steroids if weaning from mechanical ventilation is difficult $t^{30)}$. This study investigated whether dexamethasone use affects the development of preterm infants at our institution. Although the cumulative dose of dexamethasone did not affect development at the corrected age of 1 year based on the first BSID-III test, it was significantly correlated with low second BSID-III scores at the corrected age of 2 years. The long-term adverse effects of dexamethasone use might have contributed to the lower second BSID-III scores of the 36 infants who completed the two BSID-III tests at 1-year intervals. However, history of drug administration is not the only factor that affects development. Environmental factors, such as post-discharge parental nurture and nutrition, can also have a large effect. Considering the small sample size of this study, it cannot be concluded that the long-term adverse 
effects of dexamethasone cause developmental delay. A largescale, well-designed, prospective study with a long-term followup is needed to address this issue.

In this study, some infants without severe brain lesions, who were not administered dexamethasone, showed developmental delay. Among them, five patients showed diffuse excessive high signal intensity (DEHSI). While prior studies have reported a correlation between severe white matter damage and neuro developmental delay, more recent studies have reported no such correlation $^{31-37)}$. Therefore, this study did not include DEHSI as a severe brain lesion. Twenty-four patients in our study showed DEHSI; however, $76 \%$ of these patients $(n=19)$ showed normal development, suggesting that DEHSI may not be considered a severe brain lesion. Our results showed that developmental delay occurs in VLBWIs lacking severe brain injuries and post natal dexamethasone administration. Without follow-up de velopmental assessments, a caregiver may notice the delay only after it has already progressed significantly and the optimal timing for rehabilitative therapy has been missed. Therefore, a follow-up assessment to determine whether development occurs at an expected rate is necessary for early screening and treatment.

This study has several limitations. This study had a small sample size given that it was a single-center study, and the incidence of BSID-III test administration was low (40\%) among the participating infants. Additionally, as this was a retrospective study, the time at which the BSID-III test was administered varied among the infants and the history of rehabilitative therapy before the developmental assessments was not considered. Finally, hydrocortisone use was not considered, even though some infants had a history of hydrocortisone administration; therefore, the total effect of steroid uses could not be assessed.

However, because this study was conducted at a single institution, it was possible to assess the developmental state of VLBWIs discharged without severe brain lesions after they receiving uniform care under the same guidelines. This study differed from previous studies that have reported severe brain injuries as a major risk factor for developmental delay, as it assessed the risk factors for developmental delay in preterm infants without severe brain lesions. Additionally, this study monitored improvements in or worsening of developmental delay during the followup appointments. In NICUs, it is common to observe parents obsess over the brain MRI results of their preterm infants during hospitalization. If no severe brain lesions are detected, parents tend to ignore the doctor's recommendation to pursue followup developmental assessment. This study demonstrated that preterm infants without severe brain lesions can still experience developmental delay that may persist as age. This finding may help healthcare professionals and parents of preterm infants recognize the importance of developmental follow-up. A multi disciplinary effort from healthcare professionals is needed to ensure systematic, long-term follow-up and management, in addition to a large-scale prospective study examining the posi tive effects of such efforts on the development of VLBWIs.

\section{ARTICLE INFORMATION}

\section{Ethical statement}

This study was approved by the Institutional Review Board of the Pusan National University Hospital (IRB No. 05-2021-297). The requirement for informed consent was waived by the board.

\section{Conflicts of interest}

No potential conflict of interest relevant to this article was reported.

\section{Author contributions}

Conception or design: M.H.J., Y.M.H.

Acquisition, analysis, or interpretation of data: M.H.J., S.H.J., S.J.P., N.L., M.H.B., K.H.P., S.Y.B., C.K., Y.M.H.

Drafting the work or revising: M.H.J., Y.M.H.

Final approval of the manuscript: All authors read and approved the final manuscript.

\section{ORCID}

Mun Hui Jeong https://orcid.org/0000-0002-5073-7276

Seong Hee Jeong https://orcid.org/0000-0003-4811-3103

Su Jeong Park https://orcid.org/0000-0001-7496-7159

Narae Lee https://orcid.org/0000-0002-8281-6550

Mi-Hye Bae https://orcid.org/0000-0001-7168-5084

Kyung-Hee Park https://orcid.org/0000-0002-1028-4225

Shin-Yun Byun https://orcid.org/0000-0002-9034-5533

Choongrak Kim https://orcid.org/0000-0002-3096-7875

Young Mi Han https://orcid.org/0000-0002-6120-0490

\section{Funding}

None 


\section{Acknowledgments}

None

\section{REFERENCES}

1. Kim JK, Chang YS, Sung S, Ahn SY, Yoo HS, Park WS. Trends in survival and incidence of bronchopulmonary dysplasia in extremely preterm infants at 23-26 weeks gestation. J Korean Med Sci 2016;31:423-9.

2. Stoll BJ, Hansen NI, Bell EF, Walsh MC, Carlo WA, Shankaran $\mathrm{S}$, et al. Trends in care practices, morbidity, and mortality of ex tremely preterm neonates, 1993-2012. JAMA 2015;314:1039-51.

3. Woodward LJ, Anderson PJ, Austin NC, Howard K, Inder TE. Neonatal MRI to predict neurodevelopmental outcomes in preterm infants. N Engl J Med 2006;355:685-94.

4. Jeng SF, Hsu CH, Tsao PN, Chou HC, Lee WT, Kao HA, et al. Bronchopulmonary dysplasia predicts adverse developmental and clinical outcomes in very-low-birthweight infants. Dev Med Child Neurol 2008;50:51-7.

5. Grier DG, Halliday HL. Corticosteroids in the prevention and management of bronchopulmonary dysplasia. Semin Neonatol 2003;8:83-91.

6. Sharp M, DeMauro SB. Counterbalanced comparison of the BSID-II and Bayley-III at eighteen to twenty-two months corrected age. J Dev Behav Pediatr 2017;38:322-9.

7. Johnson S, Moore T, Marlow N. Using the Bayley-III to assess neurodevelopmental delay: which cut-off should be used? Pediatr Res 2014;75:670-4.

8. Ehrenkranz RA, Dusick AM, Vohr BR, Wright LL, Wrage LA, Poole WK. Growth in the neonatal intensive care unit influences neurodevelopmental and growth outcomes of extremely low birth weight infants. Pediatrics 2006;117:1253-61.

9. Jobe AH, Bancalari E. Bronchopulmonary dysplasia. Am J Respir Crit Care Med 2001;163:1723-9.

10. Ahn SH, Kim SA. Assessment of preterm infants using the Bayley-III scales in Korea. Ann Rehabil Med 2017;41:843-50.

11. Guerra CC, Barros MC, Goulart AL, Fernandes LV, Kopelman BI, Santos AM. Premature infants with birth weights of 1500-1999 g exhibit considerable delays in several developmental areas. Acta Paediatr 2014;103:e1-6.

12. Chang YS, Ahn SY, Park WS. The establishment of the Korean Neonatal Network(KNN). Neonatal Med 2013;20:169-78.

13. The Executive Committee of Korean Neonatal Network. 2016 Korean Neonatal Network Annual Report. Cheongju: Korean Centers for Disease Control and Prevention, 2017:4-63.

14. The Executive Committee of Korean Neonatal Network. 2020 Korean Neonatal Network Annual Report. Cheongju: Korean Centers for Disease Control and Prevention, 2021:4-68.
15. The Executive Committee of Korean Neonatal Network. 2017 Korean Neonatal Network Annual Report. Cheongju: Korean Centers for Disease Control and Prevention, 2018:4-65.

16. The Executive Committee of Korean Neonatal Network. 2018 Korean Neonatal Network Annual Report. Cheongju: Korean Centers for Disease Control and Prevention, 2021:4-68.

17. The Executive Committee of Korean Neonatal Network. 2019 Korean Neonatal Network Annual Report. Cheongju: Korean Centers for Disease Control and Prevention, 2021:4-68.

18. Cha JH, ChoiN, Kim YJ, LeeHJ, Kim CR, ParkHK. Developmental outcome of very-low-birth-weight infants without major brain injuries based on data from the Korean Neonatal Network: a nationwide cohort study. Neonatal Med 2020;27:151-8.

19. Sansavini A, Guarini A, Justice LM, Savini S, Broccoli S, Alessandroni R, et al. Does preterm birth increase a child's risk for language impairment? Early Hum Dev 2010;86:765-72.

20. Kiechl-Kohlendorfer U, Ralser E, Pupp Peglow U, Reiter G, Trawoger R. Adverse neurodevelopmental outcome in preterm infants: risk factor profiles for different gestational ages. Acta Paediatr 2009;98:792-6.

21. Kerstjens JM, Bocca-Tjeertes IF, de Winter AF, Reijneveld SA, Bos AF. Neonatal morbidities and developmental delay in moderately preterm-born children. Pediatrics 2012;130:e26572 .

22. Twilhaar ES, Wade RM, de Kieviet JF, van Goudoever JB, van Elburg RM, Oosterlaan J. Cognitive outcomes of children born extremely or very preterm since the 1990s and associated risk factors: a meta-analysis and meta-regression. JAMA Pediatr 2018;172:361-7.

23. Gentle SJ, Carlo WA, Tan S, Gargano M, Ambalavanan N, Chawla $\mathrm{S}$, et al. Association of antenatal corticosteroids and magnesium sulfate therapy with neurodevelopmental outcome in extremely preterm children. Obstet Gynecol 2020;135:1377-86.

24. Srinivas Jois R. Neurodevelopmental outcome of late-preterm infants: a pragmatic review. Aust J Gen Pract 2018;47:776-81.

25. Malavolti AM, Bassler D, Arlettaz-Mieth R, Faldella G, Latal B, Natalucci G. Bronchopulmonary dysplasia-impact of severity and timing of diagnosis on neurodevelopment of preterm infants: a retrospective cohort study. BMJ Paediatr Open 2018;2: e000165.

26. Wood NS, Costeloe K, Gibson AT, Hennessy EM, Marlow $\mathrm{N}$, Wilkinson AR, et al. The EPICure study: associations and antecedents of neurological and developmental disability at 30 months of age following extremely preterm birth. Arch Dis Child Fetal Neonatal Ed 2005;90:F134-40.

27. Wilson-Costello D, Walsh MC, Langer JC, Guillet R, Laptook AR, Stoll BJ, et al. Impact of postnatal corticosteroid use on neurodevelopment at 18 to 22 months' adjusted age: effects of dose, timing, and risk of bronchopulmonary dysplasia in extremely low birth weight infants. Pediatrics 2009;123:e430-7. 
28. Davidovitch M, Kuint J, Lerner-Geva L, Zaslavsky-Paltiel I, Rotem RS, Chodick G, et al. Postnatal steroid therapy is associated with autism spectrum disorder in children and adolescents of very low birth weight infants. Pediatr Res 2020;87:1045-51.

29. Doyle LW, Halliday HL, Ehrenkranz RA, Davis PG, Sinclair JC. An update on the impact of postnatal systemic corticosteroids on mortality and cerebral palsy in preterm infants: effect modification by risk of bronchopulmonary dysplasia. J Pediatr 2014;165:1258-60.

30. Doyle LW, Cheong JL, Ehrenkranz RA, Halliday HL. Late (> 7 days) systemic postnatal corticosteroids for prevention of bronchopulmonary dysplasia in preterm infants. Cochrane Database Syst Rev 2017;10:CD001145.

31. Wood NS, Marlow N, Costeloe K, Gibson AT, Wilkinson AR. Neurologic and developmental disability after extremely preterm birth. EPICure Study Group. N Engl J Med 2000;343:378-84.

32. Maalouf EF, Duggan PJ, Rutherford MA, Counsell SJ, Fletcher AM, Battin M, et al. Magnetic resonance imaging of the brain in a cohort of extremely preterm infants. J Pediatr 1999;135:351-7.
33. Volpe JJ. Cerebral white matter injury of the premature infantmore common than you think. Pediatrics 2003;112(1 Pt 1):17680.

34. de Bruine FT, van den Berg-Huysmans AA, Leijser LM, Rijken M, Steggerda SJ, van der Grond J, et al. Clinical implications of MR imaging findings in the white matter in very preterm infants: a 2-year follow-up study. Radiology 2011;261:899-906.

35. Brostrom L, Bolk J, Padilla N, Skiold B, Eklof E, Martensson G, et al. Clinical implications of diffuse excessive high signal intensity (DEHSI) on neonatal MRI in school age children born extremely preterm. PLoS One 2016;11:e0149578.

36. Murner-Lavanchy IM, Kidokoro H, Thompson DK, Doyle LW, Cheong J, Hunt RW, et al. Thirteen-year outcomes in very preterm children associated with diffuse excessive high signal intensity on neonatal magnetic resonance imaging. J Pediatr 2019;206:66-71.

37. Rath CP, Desai S, Rao SC, Patole S. Diffuse excessive high signal intensity on term equivalent MRI does not predict disability: a systematic review and meta-analysis. Arch Dis Child Fetal Neonatal Ed 2021;106:9-16. 